\title{
Multidimensional patterns of neuronal activity: how do we see them?
}

\author{
Ovidiu F Jurjut*1,2,3, Danko Nikolić1,2, Wolf Singer ${ }^{1,2}$, Dirk Metzler ${ }^{4}$ and \\ Raul C Mureşan ${ }^{2,3}$
}

Address: ${ }^{1}$ Department of Theoretical Neuroscience, Frankfurt Institute for Advanced Studies, Frankfurt am Main, Germany, ${ }^{2}$ Department of Neurophysiology, Max-Planck Institute for Brain Research, Frankfurt am Main, Germany, ${ }^{3}$ Experimental and Theoretical Neuroscience, Center for Cognitive and Neural Studies, Cluj-Napoca, Romania and ${ }^{4}$ Department of Mathematics and Informatics, Johann Wolfgang Goethe University, Frankfurt am Main, Germany

Email: Ovidiu F Jurjut* - ovidiu@jurjut.ro

* Corresponding author

from Seventeenth Annual Computational Neuroscience Meeting: CNS*2008

Portland, OR, USA. 19-24 July 2008

Published: II July 2008

BMC Neuroscience 2008, 9(SuppI I):PI 28 doi:I0.I I86/I47I-2202-9-SI-PI28

This abstract is available from: http://www.biomedcentral.com/I47I-2202/9/SI/PI 28

(c) 2008 Jurjut et al; licensee BioMed Central Ltd.

\section{Introduction}

The brain is a highly interconnected network of constantly interacting units. Understanding the collective behavior of these units requires a multi-dimensional approach. The results of such analyses are hard to visualize and interpret. Hence tools capable of dealing with such tasks become imperative.

\section{Methods}

We present a method that offers means of visualizing and interpreting the complex dynamics of a set of parallelly recorded units, in an intuitive manner. First, the activity of all simultaneously recorded neurons is represented in a multidimensional space. Second, the multidimensional space is projected on a lower dimensional (3D) space of colors, using 3D Kohonen Maps. The projection algo-
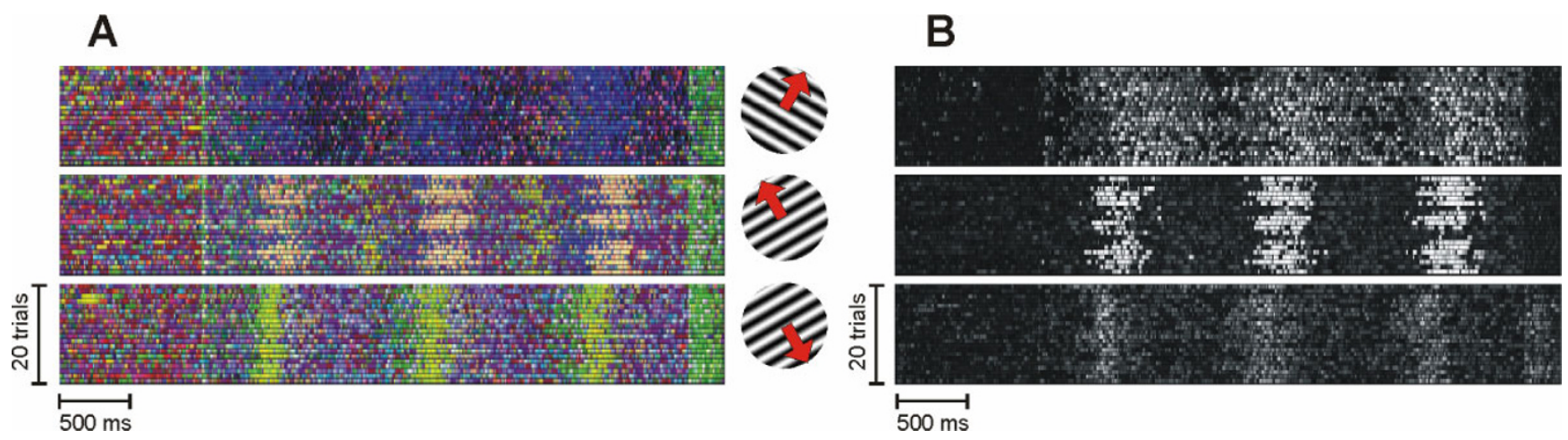

Figure I

A) Activity of 26 simultaneously recorded single units from cat area 17, stimulated with drifting sinusoidal gratings (3 direction of drift shown). Lines represent individual trials and are grouped by stimulation condition (20 trials per condition); B) Same dataset as in A but only stimulus-specific patterns are shown (white = most specific pattern). 
rithm assigns each multidimensional pattern a color in such a way that similar patterns receive similar colors. This color-coding helps our own visual system to detect patterns of activity that would be otherwise difficult to detect. Additionally, we used a simple algorithm to identify multidimensional patterns that are stimulus-specific.

\section{Results}

The method is applied to data recorded from cat area 17 under different stimulation conditions (sinusoidal gratings of different orientations). Fig. 1A shows how different gratings evoke different patterns of activity, each depicted with another color. In Fig. 1B one can observe the identified stimulus-specific patterns (light gray), that are either spread across the whole stimulus presentation period or are localized in a more narrow time window. We conclude that this visualization technique opens the way for efficient multi-dimensional exploration of neuronal data.

\section{Acknowledgements}

Research was supported by the Hertie Foundation and partially by two grants of the Romanian Government: RP-5/2007, Contract I/I. 10.2007 and ID_48/2007, Contract Nr. 204/I. 10.2007 financed by MECT/UEFISCSU and a Max Planck-Coneural Partner Group.
Publish with BiolMed Central and every scientist can read your work free of charge

"BioMed Central will be the most significant development for disseminating the results of biomedical research in our lifetime. " Sir Paul Nurse, Cancer Research UK

Your research papers will be:

- available free of charge to the entire biomedical community

- peer reviewed and published immediately upon acceptance

- cited in PubMed and archived on PubMed Central

- yours - you keep the copyright

Submit your manuscript here:

http://www.biomedcentral.com/info/publishing_adv.asp 